\title{
Characterization of plasmid-mediated qnrA and qnrB genes among Enterobacteriaceae strains: quinolone resistance and ESBL production in Ismailia, Egypt
}

\author{
Samaa A. Taha ${ }^{1,2}$, Hanan Hassan Omar ${ }^{3^{*}}$ (D) and wafaa Hassan Hassan ${ }^{4}$
}

\begin{abstract}
Background: Plasmid-mediated quinolone resistance genes (PMQR) are mainly associated with clinical isolates of Enterobacteriaceae and complicate treatment of infections caused by these isolates worldwide. Extended-spectrumbeta-lactamase (ESBL)-producing bacteria are resistant to common antibiotics and also through many mechanisms, ESBL could be disabling other types of antibiotics. This study aimed to assess the prevalence of quinolone resistance and ESBL among Enterobacteriaceae strains and investigated the presence of qnrA and qnrB genes in these strains which were isolated from urinary tract infections in Ismailia, Egypt. Ninety-four Enterobacteriaceae isolates were collected from cases of UTIs admitted to the intensive care unit, Suez-Canal University Hospitals, between October 2017 and January 2018. Antibacterial susceptibility was determined by the disk diffusion method. A polymerase chain reaction assay was used to detect qnrA and qnrB resistance genes in quinolone- and fluoroquinolone-resistant and ESBL strains. Also, ciprofloxacin MIC was determined by the agar dilution method.

Results: Resistance rates were 59.6\%, 54.3\%, 53.2\%, 53.2\%, and 53.2\% to NA, LEV, NOR, CIP, and FX, respectively. Of 56 NA-resistant isolates, 7 (12.5\%) and 6 (10.7\%) were positive for qnrA and qnrB, respectively, with only one isolate coharboring both genes. ESBL-producing bacteria was $66.2 \%$ of isolates. The MICs for ciprofloxacin ranged from 32-256 $\mu \mathrm{g} / \mathrm{ml}$ in ciprofloxacin-resistant isolates.

Conclusion: Our study shows high resistance rates of Enterobacteriaceae to quinolones and ESBL in our hospital which necessitate appropriate use of these antibiotics to reserve their application for therapy. The prevalence of quinolone-resistant and ESBL-producing Enterobacteriaceae was approximately $60 \%$ and $70 \%$ respectively.
\end{abstract}

Keywords: Enterobacteriaceae, Extended-spectrum-beta-lactamase, Fluoroquinolone, Genes, Resistance

\section{Background}

Enterobacteriaceae is a family of Gram-negative, nonspore-forming bacteria which could be involved in important critical infection mainly causing the majority of urinary tract infections (UTIs) in both community and healthcare settings [1]. These types of infections are initially treated empirically based on frequency of pathogens, local antimicrobial resistance rates and illness severity [2].

\footnotetext{
*Correspondence: hananhassan1978@gmail.com

${ }^{3}$ Department of Clinical Pathology, Faculty of Medicine, Suez Canal

University, Ismailia, Egypt

Full list of author information is available at the end of the article
}

Fluoroquinolones (FQs) are synthetic chemical artificial substance agents that a lot of physicians preferred to use these drugs as initial and first agents for empiric therapy because of their high bacteriological and clinical cure rates among uropathogens $[2,3]$.

Resistance to quinolones and beta-lactam antibiotics in Enterobacteriaceae is considered as an important common vital issue and widespread [4]. It was mostly acquired as a result of intra- or interspecies exchange of transferable plasmid-encoded antibiotic-resistant genes [5]. It commonly arises as a result of chromosomal mutations which accumulate in the genes encoding DNA 
gyrase and topoisomerase IV in quinolone resistance determining regions leading to target modification [6].

In addition, plasmid-mediated quinolone resistance (PMQR) determinants have been described, namely $q n r$ genes, aac (6')-Ib-cr, and efflux pumps genes qepA, $q e p A 2$, and $o q x A B$ [7]. The first plasmid-mediated quinolone resistance-conferring gene (qnr), now named $q n r A$, was first reported in a Klebsiella pneumoniae clinical isolate from the USA in 1998 [8]. The qnr genes protect DNA gyrase against the effect of the quinolone [9]. The qnrB is another plasmid-mediated quinolone. Resistant gene, which shares $43 \%$ amino acid identity with qnrA [10]. The horizontal transfer of plasmids which is carrying the quinolone resistance determinants beside and adjacent to the accumulation of chromosomal mutations plays an important role in increasing rates of resistance and therapeutic failure [11].

Extended-spectrum $\beta$-lactamase producing E. coli and K. pneumonia could contribute to the potential risk of antibiotic resistance spreading in clinical situations [12].

Interpretation of minimum inhibitory concentrations (MICs) of ESBL-producing Enterobacteriaceae and clinical outcome are good tools for treatment selection because the microorganisms are continuously and increasingly in developing standard therapy resistance [13].

The prevalence of extended-spectrum-beta-lactamaseproducing (ESBL) and quinolone resistance Enterobacteriaceae is increasing all over the world and infection with these bacteria strains were associated with an increase of morbidity, mortality, and health care costs $[14,15]$. In the USA, the Centers for Disease Control and Prevention demonstrated in 2013 an increase in drug-resistant microorganisms and approximately 26,000 ESBL-producing Enterobacteriaceae infections and 1700 death $s[16]$.

Little is known about the prevalence of quinolone resistance and frequency of $q n r$ genes in Enterobacteriaceae isolates recovered from urinary tract infection patients in the intensive care unit from our hospital. Therefore, the aim of this study was to assess the prevalence of quinolone resistance and ESBL and investigate the presence of plasmid-mediated qnrA and qnrB genes among the Enterobacteriaceae strains isolated from urinary tract infections of patients admitted to the intensive care unit (ICU), Suez-Canal University Hospitals, Ismailia, Egypt.

\section{Methods}

\section{Bacterial isolates}

From October 2017 to January 2018, a total of 94 nonduplicate Enterobacteriaceae strains were collected from cases of UTIs admitted to the ICU of University Hospitals. These non-duplicate isolates included Escherichia coli $(n=62)$, Klebsiella pneumonia $(n=21)$, Klebsiella oxytoka $(n=6)$, Enterobacter $(n=3)$, Citrobacter $(n=1)$ and Klebsiella ozaenae $(n=1)$.

\section{Bacterial culture}

A sample of urine was inoculated using calibrated loops in the blood and MacConkey agars. The plate was incubated aerobically at $37{ }^{\circ} \mathrm{C}$ for $24-48 \mathrm{~h}$. Conventional methods were used to identify the isolates eg: colonial morphology, Gram-staining characteristics, and biochemical tests.

\section{Antimicrobial susceptibility testing}

Antibiotic susceptibility testing was performed in this study, according to the standard Kirby-Bauer disk diffusion method on Mueller Hinton agar and interpreted according to the CLSI guidelines [17]. The MICs by the disk diffusion method were determined by the agar dilution method. All isolates were tested for the following 5 classes of antibiotics: cephalosporins (ceftazidime (CAZ $30 \mu \mathrm{g}$ ), cefotaxime (CTX $30 \mu \mathrm{g})$, and cefepime (FEP $30 \mu \mathrm{g})$ ); monobactams (aztreonam (ATM $30 \mu \mathrm{g}$ ), piperacillin (PRL $100 \mu \mathrm{g})$; carbapenems: imipenem (IMP10 $\mu \mathrm{g}$ ) and meropenem (MEM $10 \mu \mathrm{g}$ ); aminoglycoside (gentamicin (CN 10 $\mu \mathrm{g}$ ), tobramycin (TOB $10 \mu \mathrm{g}$ ), and amikacin (AK $30 \mu \mathrm{g}$ ). Quinolone and fluoroquinolone resistance was tested using nalidixic acid (NA $30 \mu \mathrm{g}$ ), norfloxacin (NOR $10 \mu \mathrm{g}$ ), levofloxacin (LEV $5 \mu \mathrm{g}$ ), ciprofloxacin (CIP $5 \mu \mathrm{g}$ ) and ofloxacin (FX $5 \mu \mathrm{g}$ ).

To confirm the presence of extended-spectrum $\beta$ lactamase (ESBL)-producing bacteria, we used ceftazidime disks with and without clavulanic acid [18]

The reference strain E. coli ATCC 25922 was used as a control. Results were interpreted as susceptible or resistant according to the criteria recommended by the CLSI and the manufacturer protocols (Mast Group, Bootle, UK).

\section{DNA extraction and $q n r$ gene amplification}

A polymerase chain reaction (PCR) assay was used to detect $q n r A$ and $q n r B$ resistance genes in quinolone, fluoroquinolone-resistant and ESBL strains (isolates found to be resistant to at least one antibiotic in the disk diffusion method).

DNA was extracted by using DNA mini-Extraction kit (Quiagen, Germany). The primers used for amplification of $q n r A$ genes were qnr A f5'-ATTTCTCACGCCAGGATT 'TG-3' and r 5'- GATCGGCAAAGGTTAGGTCA-3' and $q n r B$ gene were $\mathrm{f}-5^{\prime}$ GATCGTGAAAGCCAGAAAGG-3'r-5' - ACGATGCCTGGTAGTTGTCC-3' [10].

The amplification conditions were $5 \mathrm{~min}$ at $95{ }^{\circ} \mathrm{C}$ and 35 cycles consisting of $94{ }^{\circ} \mathrm{C}$ for $45 \mathrm{~s}, 51{ }^{\circ} \mathrm{C}$ for $45 \mathrm{~s}$ and $72{ }^{\circ} \mathrm{C}$ for $45 \mathrm{~s}$, and $72{ }^{\circ} \mathrm{C}$ for $7 \mathrm{~min}$ in the final extension [10]. The electrophoresis of PCR products was performed on $1.2 \%$ agarose gel, and then the gels were stained with ethidium bromide for $15 \mathrm{~min}$ and visualized by a gel documentation system (Biospectrum UVP, UK). 


\section{Statistical analysis}

The data was presented as mean and standard deviation or frequency and percentages. Chi-square test was used to compare between two qualitative variables and $t$ test was used to compare qualitative variables. $p$ value was significant $<0.05$. SPSS 16 software (SPSS Inc., Chicago, IL, USA) was used.

\section{Results}

\section{Antibacterial Susceptibility}

The antibiotic susceptibility results of the 94 Enterobacteriaceae isolates showed that all isolates were high resistance to cephalosporins followed by monobactams then the aminoglycosides. Resistance rates to cephalosporins were $80.9 \%, 76 \%$, and $72.3 \%$ to CAZ, CTX, and FEP, respectively. For monobactams, $78.7 \%$ to PRL and $64.9 \%$ to ATM. The resistance rates to aminoglycosides were $57.4 \%$ to $\mathrm{TOB}, 45.2 \%$ to $\mathrm{CN}$, and $40.4 \%$ to $\mathrm{AK}$. Carbapenems were the group with the least resistance as only $14.9 \%$ of all isolates were resistant to IPM and $11.7 \%$ were resistant to MEM. For quinolone and fluoroquinolone resistance, about half of all the strains showed resistance to at least one antibiotic of this group. Resistance rates were $59.6 \%, 54.3 \%, 53.2 \%, 53.2 \%$, and $53.2 \%$ to NA, LEV, NOR, CIP, and FX, respectively.

Among the 56 quinolone- and fluoroquinoloneresistant strains, 40 E.coli strains showed resistance to NA only while 37 strains showed resistance to LEV, NOR, CIP, and FX. Thirty E.coli strains were XDR, 17 were MDR and only one strain was a PDR strain. For Klebsiella spp., 15 strains showed resistance to NA only, 12 strains showed resistance to LEV only while 11 strains were resistant to NOR, CIP, and FX. Nine of the isolated Klebsiella spp. were XDR, 7 were MDR and only 5 were PDR strains. Out of the 3 Enterobacter strains, only one strain showed resistance to NA and 2 strains were resistant to LEV, NOR, CIP, and FX. Only one Enterobacter strain was a PDR strain. The sole isolated Citrobacter strain was a MDR strain and it was sensitive to the 5 quinolone and fluoroquinolone antibiotics tested (Table 1).
Of 56 NA-resistant isolates, 7 (12.5\%) and 6 (10.7\%) were positive for $q n r A$ and $q n r B$, respectively, with only one isolate co-harboring both genes. The prevalence of ESBL-producing bacteria was $66.1 \%$ and it was found that $6(12.8 \%)$ and $4(8.6 \%)$ were positive for $q n r A$ and $q n r B$, respectively (Table 2).

The MICs for CIP ranged from $32-256 \mu \mathrm{g} / \mathrm{ml}$ in the 50 isolates that showed CIP resistance in the disk diffusion test. Among the 7 isolates carried the qnrA gene, 4 isolates were E.coli and 3 were $K$. pneumoniae strains. $E$. coli strains showed MICs in the range of $64-256 \mu \mathrm{g} / \mathrm{ml}$. While the MICs were $256 \mu \mathrm{g} / \mathrm{mL}$ for $K$. pneumoniae strains (Table 3).

On the other hand, four E.coli, one K. pneumoniae, and one Enterobacter were qurB-positive isolates. Three E.coli isolates showed MIC of $128 \mu \mathrm{g} / \mathrm{mL}$ and only one strain co-harboring both genes and showed MIC of 256 $\mu \mathrm{g} / \mathrm{mL}$. The MICs for K. pneumoniae and Enterobacter isolates were $256 \mu \mathrm{g} / \mathrm{mL}$ and $32 \mu \mathrm{g} / \mathrm{mL}$, respectively (Table 3).

The relationship of quinolone and fluoroquinolone resistance, drug resistance, and ESBL-producing bacteria by disk diffusion method and $q n r A$ gene presence was a statistically insignificant while it revealed statistically significant difference only between quinolone resistant Enterobacteriaceae and $q n r B$ gene (Table 4). The majority of CIP-resistant isolates carrying qnrA genes showed complete resistance to CIP (MICs $>32 \mu \mathrm{g} / \mathrm{mL}$ ) which showed statistically significant difference while it was statistically insignificant for qnrB gene (Table 5).

\section{Discussion}

Antibiotic resistance is a difficult obstacle in our environment. It is common nowadays. Quinolones and fluoroquinolones are frequently used for the treatment of UTIs. The development of PMQR mechanisms made these infections difficult to treat as qnr genes increase resistance to NA and fluoroquinolones by four- to eightfold [19]. In this study, resistance rates to NA, LEV, NOR, CIP, and FX were indicating a high rate of resistance to quinolones and fluoroquinolones by

Table 1 Percentage of quinolone resistance, MDR, XDR, and PDR among the isolated Enterobacteriaceae strains

\begin{tabular}{lllll}
\hline Enterobacteriaceae strains \% resistance & E.coli & Klebsiella spp. & Enterobacter & Citrobacter \\
\hline NA & 40 & 15 & 1 & 0 \\
NOR & 37 & 11 & 2 & 0 \\
CIP & 37 & 11 & 2 & 0 \\
LEV & 37 & 12 & 2 & 0 \\
FX & 37 & 11 & 0 & 1 \\
MDR & 17 & 7 & 0 & 0 \\
XDR & 30 & 9 & 1 & 0 \\
PDR & 1 & 5 & & \\
\hline
\end{tabular}

MDR: multidrug resistant, $X D R$ : extensively drug resistant, $P D R$ : pan drug resistant 
Table 2 qnrA and qnrB genes among quinolone-resistant and ESBL Enterobacteriaceae and prevalence of ESBL production

\begin{tabular}{|c|c|c|c|}
\hline \multicolumn{2}{|c|}{ Enterobacteriaceae } & Number & Percent (100\%) \\
\hline \multicolumn{4}{|c|}{ Quinolone-resistant enterobacteriaceae $(n=56)$} \\
\hline \multirow[t]{2}{*}{ qnrA } & Negative & 49 & 87.5 \\
\hline & Positive & 7 & 12.5 \\
\hline \multirow[t]{2}{*}{ qnrB } & Negative & 50 & 89.3 \\
\hline & Positive & 6 & 10.7 \\
\hline \multicolumn{4}{|c|}{$\operatorname{ESBL}(n=71)$} \\
\hline & Negative & 24 & 33.8 \\
\hline & Positive & 47 & 66.2 \\
\hline \multicolumn{4}{|c|}{ ESBL-resistant Enterobacteriaceae $(n=47)$} \\
\hline \multirow[t]{2}{*}{ qnrA } & Negative & 41 & 87.2 \\
\hline & Positive & 6 & 12.8 \\
\hline \multirow[t]{2}{*}{ qnrB } & Negative & 43 & 91.4 \\
\hline & Positive & 4 & 8.6 \\
\hline
\end{tabular}

ESBL: extended-spectrum-beta-lactamase

Enterobacteriaceae strains isolated from ICU of University Hospitals. This could be due to the inappropriate use of these drugs in the treatment of UTIs. The resistance rate for NA is the highest as it has been used for the treatment of UTIs for more than five decades since its development in 1962 [20].

High prevalence of quinolone resistance in Enterobacteriaceae, particularly in E. coli, have been described in Europe, South America, and Asia and other studies in most parts of the world have indicated that it is increasing $[19,21-23]$.

In Iran and Pakistan, the frequencies of NA and CIP resistance among $E$. coli isolated from UTIs were (82.8 and $45 \%)$ and (84.2\% and $36.5 \%)$, respectively, which is in agreement with our findings [24, 25]. In addition, a study in China showed the frequency of CIP resistance to have increased to $59.4 \%$ [26].

On the other hand, our findings are in contrast to Moreno and his colleagues (2006) whose study was conducted in the USA. Their study showed that $21 \%$ and $12 \%$ of uropathogenic E. coli were resistant to quinolones and fluoroquinolones, respectively [27]. This could be due to many reasons including the situation of drug use as many people in our country take antimicrobial drugs without a prescription and over-the-counter use of quinolones in veterinary medicine, as well as environmental conditions.

Plasmid-mediated quinolone resistance determinants have been mostly identified in clinical isolates of Enterobacteriaceae and shown to play not only an important role in quinolone resistance but also resistance to other antibiotics, particularly $\beta$-lactams and aminoglycosides [28]. This would explain our findings that all isolates showed high resistance to cephalosporins followed by monobactams then the aminoglycosides and most of these strains were MDR and XDR strains.

The frequency of qnrA and $q n r B$ genes in NAresistant isolates in the present study was $7(12.5 \%)$ and 6 (10.7\%), respectively. These findings showed that some $q n r A$-and $q n r B$-negative isolates were also resistant to $\mathrm{NA}$ and fluoroquinolones signifies that other $q n r$ genes or resistance mechanisms, such as mutations in the target enzyme (e.g., DNA gyrase and topoisomerase IV) and/or activation of efflux pumps, may be involved. In Greece, $10 \%$ of CIP-resistant E. coli clinical isolates were $q n r$-positive [29]. Also, In Iran, of 116 NA-resistant isolates, 14 (12.1\%) and 9 (7.8\%) were positive for qnrA and $q n r B$, respectively, which is similar to the findings of our study [24]. On the other hand, the frequency of $q n r$ genes in the present study was higher than that found in China and Japan, where the rates were only $7.5 \%$ and $6.5 \%$, respectively $[26,30]$.

According to our results, the prevalence of qnr A was $10.8 \%$ and qnr B was $8.6 \%$ in ESBL-positive bacteria from UTI isolated. Oktem et al. reported the prevalence of qnr A was $6.4 \%$ in ESBL-positive blood culture isolates collected from Turkey [5].

In contrary to our results, Shams and his colleagues (2015) investigated the ESBL-producing K. pneumoniae isolates. They reported no qnr A gene was detected in their isolates while they found approximately $46 \%$ had qnr B gene [31]. However, a previous study done by a

Table 3 Ciprofloxacin MICs values of qnrA- and qnrB-positive quinolone-resistant isolates

\begin{tabular}{lllll}
\hline Bacterial strain & number & Resistance gene & MIC of CIP $(\mu \mathrm{g} / \mathrm{mL})$ & Total $n=56(\%)$ \\
\hline E. coli & 1 & qnrA & qnrA & 128 \\
& 2 & qnrA & 256 & $7(12.5 \%)$ \\
K. pneumoniae & 1 & qnrA & 256 \\
E. coli & 3 & qnrB & 128 \\
K. pneumoniae & 3 & qnrB & 256 & 256 \\
Enterobacter & 1 & qnrB & 32 & $6(10.7 \%)$ \\
\hline
\end{tabular}


Table 4 Relationship of quinolone- and fluoroquinolone-resistant Enterobacteriaceae, drug resistance and ESBL, and qnrA and qnr B genes

\begin{tabular}{lllll}
\hline Variables & qnr A gene & $p$ & qnr B & $p$ \\
\cline { 2 - 3 } & Negative Positive & value & Negative Positive & \\
\hline
\end{tabular}

Quinolone-resistant microorganism isolated $(n=56)$

\begin{tabular}{|c|c|c|c|c|c|c|}
\hline E. coli & 36 & 4 & & 36 & 4 & \\
\hline K. pneumonia & 12 & 3 & 0.374 & 14 & 1 & $0.023^{*}$ \\
\hline Enterobacter & 1 & 0 & & 0 & 1 & \\
\hline \multicolumn{7}{|c|}{ Drug resistance $(n=71)$} \\
\hline MDR & 23 & 2 & & 24 & 1 & \\
\hline $\mathrm{XDR}$ & 34 & 5 & 0.586 & 35 & 4 & 0.573 \\
\hline PDR & 7 & 0 & & 6 & 1 & \\
\hline \multicolumn{7}{|l|}{$\operatorname{ESBL}(n=71)$} \\
\hline Negative & 23 & 1 & 0.250 & 22 & 2 & 0.980 \\
\hline Positive & 41 & 6 & & 43 & 4 & \\
\hline
\end{tabular}

$M D R$ : multidrug resistant, $X D R$ : extensively drug resistant, $P D R$ : pan drug resistant, ESBL: extended-spectrum-beta-lactamase.

number of researchers in their group demonstrated the prevalence of qnr A gene was high among E. coli bacteria [24].

The presence of a PMQR determinant increases resistance to NA and fluoroquinolones four to eight times [19]. This could explain that the majority of CIPresistant isolates carrying qnr genes had high MIC values (MICs $>32 \mu \mathrm{g} / \mathrm{mL}$ ) in our study.

In the current study, ESBL-producing Enterobacteriaceae was more than half of the isolates. In contrast to our results, Azargun et al. (2018) reported the 34.2\% of their isolates were ESBL-producing and $K$. pneumoniae was $53.5 \%$ then E. coli was $33.8 \%$ [32]. However Rao et al. (2014) found $61.4 \%$ of ESBL production among E. coli and $46.2 \%$ among K. pneumoniae [33]. In South

Table 5 ciprofloxacin MICs values of qnr A and qur B genes positive quinolone resistant isolated specimens

\begin{tabular}{|c|c|c|c|}
\hline \multirow{2}{*}{$\begin{array}{l}\text { Resistant } \\
\text { isolated } \\
\text { specimens }\end{array}$} & \multicolumn{2}{|c|}{ ciprofloxacin MICs values } & \multirow{2}{*}{$\begin{array}{l}p \\
\text { value }\end{array}$} \\
\hline & mean & $\pm \mathrm{SD}$ & \\
\hline qnrA & & & $0.002^{*}$ \\
\hline Negative & 89.9 & \pm 74 & \\
\hline Positive & 192 & \pm 82 & \\
\hline \multicolumn{4}{|l|}{ qnrB } \\
\hline Negative & 97.7 & \pm 81 & 0.119 \\
\hline Positive & 154.6 & \pm 86 & \\
\hline \multicolumn{4}{|l|}{ ESBL } \\
\hline Negative & 84.89 & \pm 85.24 & 0.203 \\
\hline Positive & 116.8 & \pm 81.38 & \\
\hline
\end{tabular}

MICs: minimal inhibitory concentrations;

ESBL: extended-spectrum-beta-lactamase
Korea, 30\% of isolates were reported positive for ESBL. Karami et al. (2017) investigated the stool samples of Iranian children. They found approximately $80 \%$ of the isolates were ESBL-producing enteropathogenic E. coli [34]. In addition, in the north of Iran, among the 160 clinical E. coli isolates, 83 (51.9\%) were ESBL-positive [35]. The difference between these results could have resulted from several factors such as the variety in species, geographical regions, the length of ICU stay and increase using of antibiotics.

\section{Conclusion}

In conclusion, the resistance rate of Enterobacteriaceae isolated from UTIs to fluoroquinolones and $\beta$-lactams is high in ICU in our hospital. The prevalence of quinoloneresistant and ESBL-producing Enterobacteriaceae was approximately $60 \%$ and $70 \%$ respectively. Our findings showed high frequencies of $q n r A$ and $q \eta r B$ genes in UTI isolates of Enterobacteriaceae. Therefore, detection of plasmid-mediated qnrA and qnrB genes among quinoloneresistant and ESBL-producing Enterobacteriaceae is important for appropriate empirical treatment and infection control. Moreover, appropriate use of these antibiotics will limit the potential spread of resistant genes and reserve their application for therapeutic uses.

\section{Abbreviations}

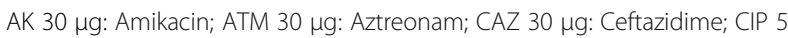

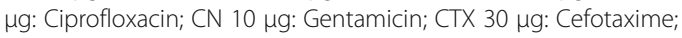

ESBL: Extended-spectrum-beta-lactamase-producing; FEP 30 нg: Cefepime;

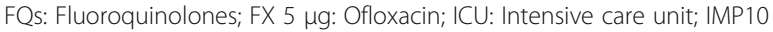

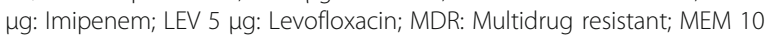

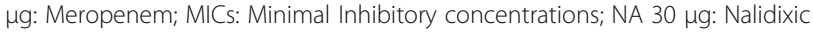
acid; NOR 10 g: Norfloxacin; PCR: Polymerase chain reaction; PDR: Pan drug resistant; PMQR: Plasmid-mediated quinolone resistance genes; PRL 100 $\mu \mathrm{g}$ : Piperacillin; qnr: Quinolone resistance-conferring gene; TOB 10 mg: Tobramycin; UTIs: Urinary tract infections; XDR: Extensively drug resistant

\section{Acknowledgements}

Not applicable.

\section{Authors' contributions}

All authors have seen and approved the manuscript, contributed significantly to the work, and also that the manuscript has not been previously published in or is not being considered for publication elsewhere. ST: design of the study, interpretation of data, drafting the article and final approval HO: design of the study, analysis of the data, editing and final revision WH: acquisition of data, interpretation of data, drafting the article and final revision.

\section{Funding}

No funding was obtained for this study. This work was done by the authors' own funding.

\section{Availability of data and materials}

Data will not be shared due to the policy of our institute.

\section{Ethics approval and consent to participate}

The study was approved by the Ethics Committee at the Faculty of Medicine, Suez Canal University, Egypt.

Informed verbal consent was taken from all cases included in the study because no personal or clinical data were included. The study was done on the microorganisms found in the urine specimens.

Reference number: not applicable. 


\section{Consent for publication}

Not applicable.

\section{Competing interests}

The authors declare that they have no competing interests.

\section{Author details}

'Department of Microbiology, College of Medicine, Taif University, Al-Taif, Saudi Arabia. ${ }^{2}$ Department of Microbiology and Medical Immunology, Faculty of Medicine, Suez Canal University, Ismailia, Egypt. ${ }^{3}$ Department of Clinical Pathology, Faculty of Medicine, Suez Canal University, Ismailia, Egypt. ${ }^{4}$ infectious and endemic department, faculty of medicine, Suez Canal University, Ismailia, Egypt.

Received: 23 May 2019 Accepted: 21 September 2019

Published online: 25 November 2019

\section{References}

1. Gupta K, Hooton TM, Naber KG, Wullt B, Colgan R, Miller LG, Moran GJ, Nicolle LE, Raz R, Schaeffer AJ, Soper DE (2011) International clinical practice guidelines for the treatment of acute uncomplicated cystitis and pyelonephritis in women: A 2010 update by the Infectious Diseases Society of America and the European Society for Microbiology and Infectious Diseases. Clin Infect Dis 52(5):e103-e120

2. Gururaju T, Kasturi T, Mallikarjuna reddy C. (2015) A study of antibiotic sensitivity pattern and detection of fluoroquinolones resistance to Escherichia coli from urinary tract infections. Int J Curr Microbiol App Sci 4(2):799-805

3. Yamane K, Wachino J, Suzuki S, Kimura K, Shibata N, Kato H, Shibayama K, Konda T, Arakawa Y (2007) New plasmid-mediated fluoroquinolone efflux pump, QepA, found in an Escherichia coli clinical isolate. Antimicrob Agents Chemother 51(9):3354-3360

4. Yang HY, Nam YS, Lee HJ (2014) Prevalence of plasmid-mediated quinolone resistance genes among ciprofloxacin-nonsusceptible Escherichia coli and Klebsiella pneumoniae isolated from blood cultures in Korea. Can J Infect Dis Med Microbiol 25(3):163-169

5. Oktem IM, Gulay Z, Bicmen M, Gur D (2008) gnrA prevalence in extendedspectrum beta-lactamase-positive Enterobacteriaceae isolates from Turkey. Jpn J Infect Dis 61(1):13-17

6. Ruiz J (2003) Mechanisms of resistance to quinolones: target alterations, decreased accumulation and DNA gyrase protection. J Antimicrob Chemother 51(5):1109-1117

7. Kocsis B, Mazzariol A, Kocsis E, Koncan R, Fontana R, Cornaglia G (2013) Prevalence of plasmid-mediated quinolone resistance determinants in Enterobacteriaceae strains isolated in North-East Italy. J Chemother (Florence, Italy) 25(1):36-40

8. Jacoby GA, Chow N, Waites KB (2003) Prevalence of plasmid-mediated quinolone resistance. Antimicrob Agents Chemother 47(2):559-562

9. Wang M, Sahm DF, Jacoby GA, Hooper DC (2004) Emerging plasmidmediated quinolone resistance associated with the qnr gene in Klebsiella pneumoniae clinical isolates in the United States. Antimicrob Agents Chemother 48(4):1295-1299

10. Stephenson S, Brown PD, Holness A, Wilks M (2010) The emergence of qurmediated quinolone resistance among Enterobacteriaceae in Jamaica. West Indian Med J 59(3):241-244

11. Bouchakour M, Zerouali K, Gros Claude JD, Amarouch H, El Mdaghri N, Courvalin P, Timinouni M (2010) Plasmid-mediated quinolone resistance in expanded spectrum beta lactamase producing enterobacteriaceae in Morocco. J Infect Dev Ctries 4(12):779-803

12. Hoseini N, Sedighi I, Nejad A, Alikhani M (2017) Phenotypic and Genotypic Detection of AmpC Enzymes in Clinical Isolates of Escherichia coli and Klebsiella pneumoniae. J Krishna Institute of Med Sci University 6(3):10-18

13. Esterly JS, Wagner J, McLaughlin MM, Postelnick MJ, Qi C, Scheetz MH (2012) Evaluation of clinical outcomes in patients with bloodstream infections due to Gram-negative bacteria according to carbapenem MIC stratification. Antimicrob Agents Chemother 56(9):4885-4890

14. Akinbami OR, Olofinsae S, Ayeni FA (2018) Prevalence of extended spectrum beta lactamase and plasmid mediated quinolone resistant genes in strains of Klebsiella pneumonia, Morganella morganii, Leclercia adecarboxylata and Citrobacter freundii isolated from poultry in South Western Nigeria. Peer J 6:e5053-e
15. Flokas ME, Karanika S, Alevizakos M, Mylonakis E (2017) Prevalence of ESBL-Producing Enterobacteriaceae in Pediatric Bloodstream Infections: A Systematic Review and Meta-Analysis. PloS one 12(1): e0171216-e

16. States. ArtitU. (2017) http://www.cdc.gov/drugresistance/threat-report-2013.

17. Franklin R, Cockerill I (2011) Performance Standards for Antimicrobial Susceptibility Testing, Twenty-First Informational Supplement M100-S21. Clinical and Laboratory Standard Institute 31:68-80

18. Singh RM, Singh HL (2014) Comparative evaluation of six phenotypic methods for detecting extended-spectrum beta-lactamase-producing Enterobacteriaceae. The Journal of Infection in Developing Countries 8(04): 408-415

19. Hooper DC (2001) Emerging mechanisms of fluoroquinolone resistance. Emerging infectious diseases 7(2):337-341

20. Emmerson AM, Jones AM (2003) The quinolones: decades of development and use. The Journal of antimicrobial chemotherapy 51 Suppl 1:13-20

21. Karlowsky JA, Hoban DJ, Decorby MR, Laing NM, Zhanel GG (2006) Fluoroquinolone-resistant urinary isolates of Escherichia coli from outpatients are frequently multidrug resistant: results from the North American Urinary Tract Infection Collaborative Alliance-Quinolone Resistance study. Antimicrobial agents and chemotherapy 50(6):22512254

22. Kariuki S, Revathi G, Corkill J, Kiiru J, Mwituria J, Mirza N, Hart CA.(2007) Escherichia coli from community-acquired urinary tract infections resistant to fluoroquinolones and extended-spectrum beta-lactams. Journal of infection in developing countries.1(3):257-62.

23. Yamane K, Wachino J, Suzuki S, Arakawa Y (2008) Plasmid-mediated qepA gene among Escherichia coli clinical isolates from Japan. Antimicrobial agents and chemotherapy 52(4):1564-1566

24. Firoozeh F, Zibaei M, Soleimani-Asl Y (2014) Detection of plasmid-mediated gnr genes among the quinolone-resistant Escherichia coli isolates in Iran. J Infect Dev Ctries 8(7):818-822

25. Muhammad I, Uzma M, Yasmin B, Mehmood Q, Habib B (2011) Prevalence of antimicrobial resistance and integrons in Escherichia coli from Punjab, Pakistan. Braz J Microbiol 42(2):462-466

26. Wang A, Yang Y, Lu Q, Wang Y, Chen Y, Deng L et al (2008) Presence of gnr gene in Escherichia coli and Klebsiella pneumoniae resistant to ciprofloxacin isolated from pediatric patients in China. BMC infectious dis 8:68

27. Moreno E, Prats G, Sabate M, Perez T, Johnson JR, Andreu A (2006) Quinolone, fluoroquinolone and trimethoprim/sulfamethoxazole resistance in relation to virulence determinants and phylogenetic background among uropathogenic Escherichia coli. J Antimicrob Chemother 57(2):204-211

28. Robicsek A, Jacoby GA, Hooper DC (2006) The worldwide emergence of plasmid-mediated quinolone resistance. Lancet Infect Dis 6(10):629-640

29. Vasilaki O, Ntokou E, Ikonomidis A, Sofianou D, Frantzidou F, AlexiouDaniel S, Maniatis AN, Pournaras S (2008) Emergence of the plasmidmediated quinolone resistance gene qnrS1 in Escherichia coli isolates in Greece. Antimicrob Agents Chemother 52(8):2996-2997

30. Ode T, Saito R, Kumita W, Sato K, Okugawa S, Moriya K, Koike K, Okamura N (2009) Analysis of plasmid-mediated multidrug resistance in Escherichia coli and Klebsiella oxytoca isolates from clinical specimens in Japan. Int J Antimicrob Agents 34(4):347-350

31. Shams E, Firoozeh F, Moniri R, Zibaei M (2015) Prevalence of PlasmidMediated Quinolone Resistance Genes among Extended-Spectrum $\beta$ Lactamase-Producing Klebsiella pneumoniae Human Isolates in Iran. Journal of Pathogens. 2015:7

32. Azargun R, Sadeghi MR, Soroush Barhaghi MH, Samadi Kafil H, Yeganeh F, Ahangar Oskouee M, Ghotaslou R (2018) The prevalence of plasmid-mediated quinolone resistance and ESBL-production in Enterobacteriaceae isolated from urinary tract infections. Infect Drug Resist 11:1007-1014

33. Rao SP, Rama PS, Gurushanthappa V, Manipura R, Srinivasan K (2014) Extended-Spectrum Beta-Lactamases Producing Escherichia coli and Klebsiella pneumoniae: A Multi-Centric Study Across Karnataka. J Lab Physicians 6(1):7-13

34. Karami P, Bazmamoun H, Sedighi I, Mozaffari Nejad AS, Aslani MM, Alikhani MY (2017) Antibacterial resistance patterns of extended spectrum betalactamase -producing enteropathogenic Escherichia coli strains isolated from children. Arab J Gastroenterol 18(4):206-209 
35. Haghighatpanah M, Mozaffari Nejad AS, Mojtahedi A, Amirmozafari N,

Zeighami H (2016) Detection of extended-spectrum beta-lactamase (ESBL)

and plasmid-borne blaCTX-M and blaTEM genes among clinical strains of

Escherichia coli isolated from patients in the north of Iran. J Glob

Antimicrob Resist 7:110-113

\section{Publisher's Note}

Springer Nature remains neutral with regard to jurisdictional claims in published maps and institutional affiliations.

Submit your manuscript to a SpringerOpen ${ }^{\circ}$ journal and benefit from:

- Convenient online submission

- Rigorous peer review

- Open access: articles freely available online

- High visibility within the field

- Retaining the copyright to your article

Submit your next manuscript at $\boldsymbol{\nabla}$ springeropen.com 